\title{
Innovation of Undergraduate Teaching under the Background of
}

\section{Knowledge Fragmentation}

\author{
Zhang Jin \\ Wuhan Institute of Design and Sciences, Wuhan City, Hubei Province \\ 346591653@163.com
}

Keywords: Fragmentation knowledge; Undergraduate teaching; Multimedia; Teaching design; Innovation

\begin{abstract}
The development of modern science and technology promotes the development of advanced network multimedia, and it provides a diversified learning resource for the public. With the help of network multimedia, we can learn anytime and anywhere, and this knowledge fragmentation phenomenon has been deeply into our work and study. Based on the author's teaching experience for many years, this paper first analyzes the development mechanism of fragmentation knowledge and then with the help of the multimedia, puts forward the new strategies of undergraduate classroom teaching under the background of knowledge fragmentation.
\end{abstract}

\section{Introduction}

4G era provides a good platform for fragmentation learning. Every man who is eager to learn will have a "fragmented" learning tools and means and strengthens learning using their own "fragments of time" every day, so they can activate their own brain that is easy to be rigid, making their work and life have a high quality of life in order to have more happy time. We can also understand the fragmentation as a kind of diversification, and fragmentation is a manifestation of the fragmentation of society or the diversification of the whole society in the nature of communication.

\section{The Development Mechanism of Fragmentation Knowledge}

The main factor to maintain the fragmentation knowledge is: notification - feedback - reward mechanism. Studies have found that people tend to frequently trigger notifications on the Internet, either by production or by receiving notifications. No matter what kind, to a certain degree of psychological satisfaction, system level can give feedback, at the same time to establish a more powerful psychological dependence. At the system level, all processes are carried out in real time. Behavior will affect the thinking, there are a large number of examples show that after a number of consecutive clearance in the moderate difficulty of the game, the confidence of the experimental subjects will improve, in a more difficult games, they will have a more outstanding performance.

After the notice -- feedback -- incentive mechanism is established, it will have an impact on people's way of thinking. Some people have done the following experiments: Within 100 words, at the beginning it gives a clear argument and supports the discussion with two sentences, but at the end, the conclusion is reversed deliberately. As a result, there will be a considerable number of people who show that they have no ability to read 100 words at all. The time they read the first or the two sentence, they will make a reply or forward action. The psychologist said: the general adult 
effective attention can maintain 20min, and people will produce anxiety over this time. It can be seen that both adults and children have been accustomed to the super link browsing, attention is difficult to lasting. So, now every section of the site has a content tips, and this is the reason why micro-blog, micro-video, micro-letters and other micro derivatives will be so popular.

\section{New Strategies of Undergraduate Classroom Teaching under the Background of Knowledge Fragmentation}

Fragmentation knowledge is the product of the common development of multimedia technology and network technology, based on the current situation of undergraduate teaching, we design a set of feasible teaching methods, as shown in Figure 1.

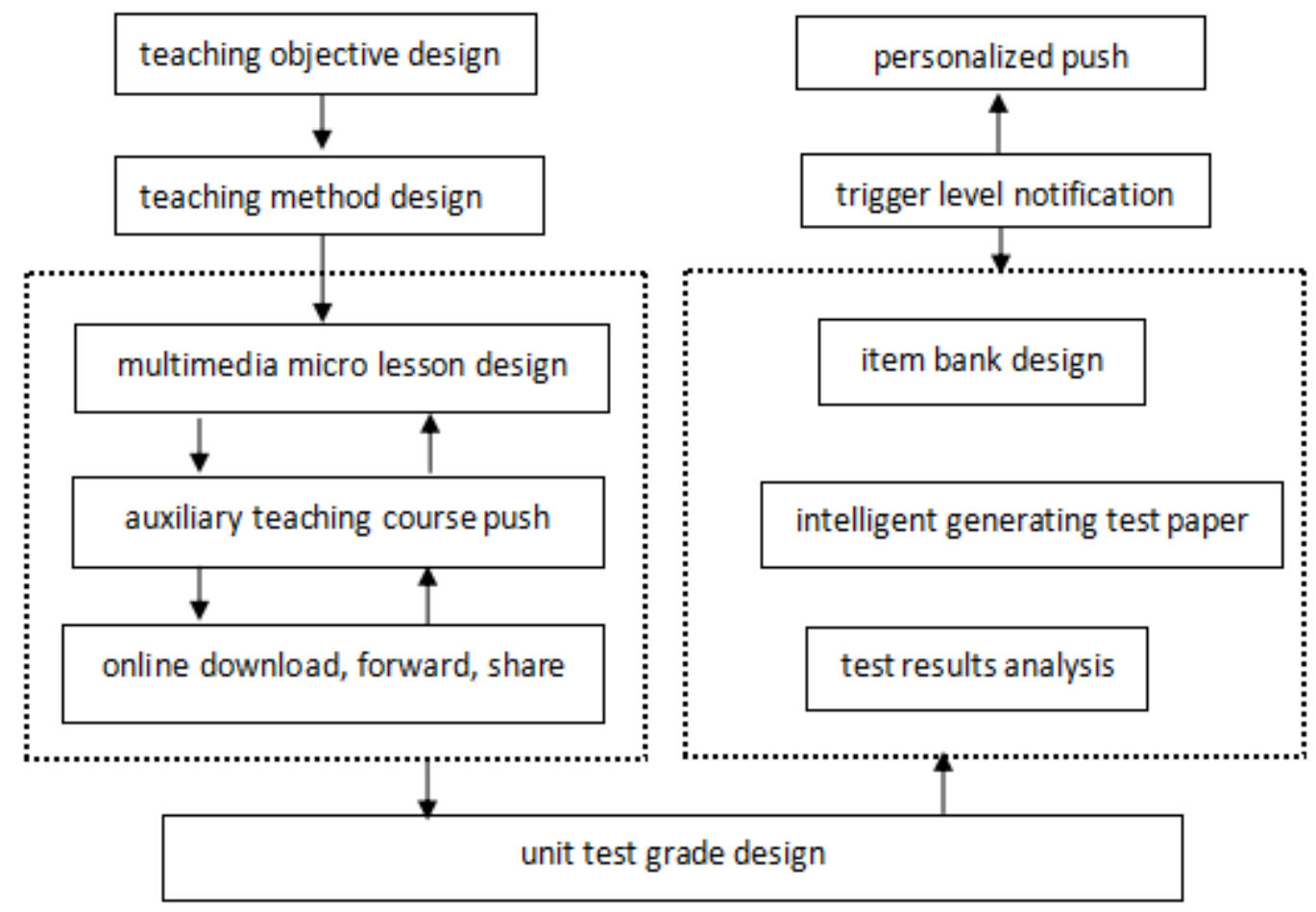

Fig.1 the teaching design method of fragmentation multimedia

Teaching objective design. The design principles and objectives should be appropriate, rather than better. Good objective design can maximize the potential of most students to achieve goals. The main methods are the following two points: one is an accurate assessment on the overall cognitive ability, including questionnaire and diagnostic test; Two is the ultimate goal of the gradient design, including the target gradient and the target interval. The target gradient design can be expressed by the linear equation of $\mathrm{Y}=\mathrm{KX}$. $\mathrm{Y}$ axis represents the target gradient; $\mathrm{X}$ axis represents the target interval; $\mathrm{K}$ is the difficulty coefficient of the teaching goal. It is concluded that If the gradient of the target is certain, the greater the difficulty coefficient, the shorter the gradient of the target. The degree of fragmentation of multimedia knowledge points will be smaller and smaller. Conversely, if the target interval (hours) is certain, the target's degree coefficient is bigger, and the target gradient is higher. It can be seen that the teaching goal difficulty coefficient is proportional to the target gradient, and is inversely proportional to the target distance. That is, the difficulty coefficient of the teaching objective determines the fine degree of multimedia fragmentation, and it is also the basic principle of the fragmentation of the media.

Teaching method design. Using computer multimedia technology and network technology to build a network teaching platform is a good way to assisted instruction. In the teaching method, it 
is able to realize the diversity of media means, in the teaching method, it breaks through the traditional space and time limit, realizing the maximum degree of teaching resources sharing. In the era of fragmentation of reading, we have been unable to find a way to adapt to the best teaching, therefore, the diversity of teaching methods and adaptive design is particularly important. For example: the teaching method design of automobile driving training and surgical operation training must be different. However, information intelligent interactive method design using big data and cloud technology is undoubtedly the best choice and it is also a necessary element of the excellent course. But it also put forward higher requirements to the quality of the designers.

Instructional media design. If the teaching structure design is regarded as the human skeleton, the teaching media design is the human body muscle. Only bones and muscles are organically combined, people will have vitality. In modern instructional design, the design of the media has become an indispensable important part. Delicate media design will often make the teaching effect with half the effort. The emergence of rich media is undoubtedly another revolutionary contribution to educational means. Media design mainly includes: text, images, sound, animation four aspects. Application principles are: practical, enough. Media design includes two aspects:

First, the media fragmentation design. Many courses in the media have no interactive control function, such as the animation presentation can not be effectively controlled by the user; the video is not broadcast in a real streaming media. These problems make the human-computer interaction function weakened, and affect the knowledge spread. Therefore, precision fragmentation node -compression algorithm -- instant jump of personalized service push -- can be convenient to choose the circulation of broadcast content - related knowledge of instant push delivery service, super link to return to the media pointer -- out of the accident after the fast positioning, rich media and path selection, these design skills are an important part of the media design.

Second, the synthesis design of the media. In the digital age, the synthesis method of the media usually adopts the layer structure design method. Whether it is a picture, animation, sound, video, these are achieved through layer overlay. The synthesis design is usually based on the logical way of the thing itself. Its biggest function is to enable students to understand the principles of things change in a short time with a low cost and high efficiency. By means of time delay and acceleration technology, students can improve their learning efficiency. For example in Higher Mathematics course, every knowledge point is synthesized by the media. Through the mouse click or drag the text, the contents of the image displayed in the window and it will be displayed accordingly, at the same time, the commentary will follow up in real time. This design allows students to choose to study, and the media player is completely controlled by the students themselves.

The main points of the synthesis of streaming media are the choice of compression algorithms. Ministry of education document < National Excellent Course Video Internet Technology Standards > put forward a clear requirement: fine course video need to use streaming video on demand, and the selection principle is clear, generic, smooth, and easy to broadcast. Today, mobile media terminals are popular, low flow is often more important than high clarity. The ultimate goal of media design is to make knowledge visualization. Regulating the operation of video, schematic diagram, the principle of animation and other content plays a decisive role in regulating the teaching content, guiding and correcting the students' operation.

Self-study design. Student self study design is a branch of the overall teaching structure design, which is a necessary part of guiding students to learn. Due to the lack of necessary learning supervision, self-study design directly affects the students' self-study "jump out rate." As long as the students are curious about the situation, they can carry out active learning, and through personalized mobile devices, students can easily and quickly switch from one scenario architecture to another. In 
the design of the study, the addition of hierarchical design can effectively stimulate students' learning desire, coupled with the use of PUSH and notification mechanism, it reduces students' jump out rate", to extend the students' self-study online time, improving the effect of self-study. Ask and confirm the reason - another learning path - navigation service push - analysis to determine the reason to jump out - to guide the improvement of the target design. Forum design method is a good choice.

Teaching evaluation design. As well as teaching design, teaching evaluation design is part of the overall structural design of the teaching. The reason that gives it a separate list is the two design is an integral part of the overall structure design. At the same time, it can be independent of the overall design. The design of teaching evaluation and teaching self-study is the servo system of the whole teaching design. The conclusion of the teaching evaluation system design flaws feedback teaching structure, so as to guide and improve the teaching structure design, including the following four points: the question bank design, intelligent test paper, Score statistical analysis and structural decision making.

In the teaching evaluation design, adding the line grade design, in order to stimulate students' learning interest. Using the notification and jump, personalized navigation push service make learning step by step, accelerate the achievement of learning goals. As well as teaching design, multimedia instructional design is a process that needs to be improved. Through the system operation and the actual test, adopting a more reasonable and effective design, repairing system BUG in time, step by step to improve the network course system must be a design process that runs through the whole process.

\section{Reference}

[1] Tian Ping. "Innovative knowledge" in the era of information fragmentation [J]. Shanghai Information Technology, 2011,07:24-27.

[2] Meng Wei Gong. Modernist knowledge teaching concept of multi-dimensional Criticism -Discussion of postmodern knowledge teaching concept [J]. Science Education Research, 2008,10:14-17.

[3] Lu Jianjun, Qi Zhen. Multimedia Instructional Design based on the fragmentation of learning[J]. Chinese Medical Education Technology, 2014,05:508-511.

[4] Liu Zhen. Teaching exploration under the background of knowledge fragmentation[J]. Language Building, 2015,34:37-39. 